\title{
In Vitro Characterization of Multilamellar Fibers with Uniaxially Oriented Electrospun Type I Collagen Scaffolds
}

\author{
Alireza Hooshmand-Ardakani, ${ }^{1}$ Tahereh Talaei-Khozani, ${ }^{1}$ Mehdi Sadat-Shojai, ${ }^{2}$ \\ Soghra Bahmanpour, ${ }^{1}$ and Nehleh Zarei-fard (i) ${ }^{1}$ \\ ${ }^{1}$ Anatomy Department, School of Medicine, Shiraz University of Medical Sciences, Shiraz, Iran \\ ${ }^{2}$ Department of Chemistry, College of Sciences, Shiraz University, Shiraz, Iran \\ Correspondence should be addressed to Nehleh Zarei-fard; zareifard@sums.ac.ir
}

Received 28 July 2020; Revised 19 September 2020; Accepted 7 October 2020; Published 24 October 2020

Academic Editor: Victor M. Castaño

Copyright (c) 2020 Alireza Hooshmand-Ardakani et al. This is an open access article distributed under the Creative Commons Attribution License, which permits unrestricted use, distribution, and reproduction in any medium, provided the original work is properly cited.

\begin{abstract}
Fabrication of an appropriate scaffold is critical in order to recapitulate the architecture and functionality of the native tissue. In this study, we attempted to create favorable collagen fiber alignment and multilamellar with uniaxially oriented layers, using a disc collector by turning mats 90 degrees horizontally at specific times. Different concentrations of rat tail-derived type I collagen (3, 6 , $8 \% \mathrm{w} / \mathrm{v}$ ) in 1,1,1,3,3,3-hexafluoroisopropanol (HFIP) are used for electrospinning affairs. The $6 \% \mathrm{w} / \mathrm{v}$ collagen at an applied voltage of $20 \mathrm{kV}$ and collector rotation of $2500 \mathrm{rpm}$ was selected to exhibit bead-free homogeneous nanofiber with fiber thickness of $0.14 \pm 0.4 \mu \mathrm{m}$, maximum thickness of $0.5 \pm 0.08 \mu \mathrm{m}$, and $60 \%$ porosity. Also, scanning electron microscope images of electrospun fibers showed 3D multilamellar scaffold with the goodness of $96.5 \% \pm 0.8$ in each aligned uniaxially oriented fiber layer. Cross-linking of collagen fibers with $\mathrm{N}$-(3-dimethylaminopropyl)-N0-ethylcarbodiimide hydrochloride (EDC)/N-hydroxysuccinimide (NHS) reduced the fiber degradation rate and preserved the fiber morphology and alignment. The multilamellar mat showed significant increase in tensile strength and average breaking elongation in comparison with unilamellar mat. In vitro cell culture, using human adipose tissue-derived mesenchymal stem cells (hAT-MSCs) on cross-linked scaffold, showed improvement in cell proliferation, attachment, migration, and intercellular junction with a flattened morphology. Raman spectra revealed the preservation of collagen structure. In addition, Raman spectra of the cell containing scaffold were the same as those of an intact intervertebral disc as a sample to be used in engineering tissues. In conclusion, our results showed that the 3D multilamellar collagen nanofibrous scaffold is more appropriate for the tissues that have multilamellar structure.
\end{abstract}

\section{Introduction}

One important part of tissue engineering triad is biomaterials in the form of scaffolds. Electrospinning is one of the techniques which is used for scaffold fabrication [1-3]. Nanofibers with random and aligned orientation can be obtained from electrospinning $[4,5]$. Since producing nanofibers with high porosity and specific surface area using electrostatic force is easy and cost-effective and requires a simple system, many researchers in the field of tissue engineering are in favor of the electrospinning technique for preparing scaffolds. Strength, alignment, and diameter of electrospun nanofibers ranging from tens of nanometers to a few micrometers can be determined by factors, such as solution concentration, applied voltage, injection rate, collector type, and distance of needle tip to collector $[3,6,7]$. These characters for the electrospun fibers can control the cultured cell behavior and function [8].

It is important that morphology and structure of nanofibers should accommodate with natural extracellular matrix construct [9]. Electrospun nanofiber orientation and direction should reinforce the construct against mechanical forces exposed to a tissue $[10,11]$. Fiber alignment regulates cell migration, stimulates cell proliferation, and also more aligned fiber synthesis [12]. Some studies reported the fabrication of aligned electrospun nanofibers by utilizing 
particular fiber collectors such as a rotating cylinder or wired drum [13-15]. Although some studies focused on fabrication of uniaxially aligned electrospun nanofibers, using synthetic polymers, such as polyacrylonitrile, poly(lactic acid) (PLA), polycaprolactone (PCL), and poly(D, L-lactic-co-glycolic acid) (PLGA) [4, 16-18], a limited number of studies have focused on fabricating align collagen fibers as natural polymers [19, 20]. Aligned collagen electrospun nanofibers are superior to the synthetic polymers, as they constitute the main fibrous protein in the extracellular matrix with excellent biodegradability and biocompatibility. This protein has a significant role in the regulation of cell activity, due to its suitable mechanical strength. Mechanical strength is also influenced by pore size. As oriented fibers have smaller pore sizes, such a scaffold has higher mechanical strength [21].

Some tissues such as cornea and annulus fibrosus contain ECM with uniaxially aligned collagen fibers in multilamellar structures $[4,22]$. In these multilayered tissues, collagen fibers are oriented parallel to each other, and the orientation of fibers in each layer are perpendicular to the adjacent one. To repair the damaged tissues with multilamellar structure, engineered scaffolds have raised interest.

Comparing to the collagen polymerized in the naive position, electrospun collagen fibers have low mechanical property due to nanoscale smaller dimensions. The electrospun collagen fibers are brittle but not fragile [23]. These have encouraged the researchers to mix collagen with synthetic polymers for engineered tissues exposed to high mechanical forces [9, 23-26]. However, cross-linking of electrospun collagen can boost up the mechanical strength without affecting the biological activity of cultured cells [27]. It was reported that cross-linking of electrospun collagen scaffolds with EDC-NHS improves fiber morphology, degradation time, and stability of scaffolds $[25,28]$.

In this study, we electrospun type I collagen to produce multilamellar collagen fibers with uniaxially oriented layers, using disc collector.

\section{Materials and Methods}

2.1. Materials. 1,1,1,3,3,3-Hexafluoroisopropanol (HFIP), 1-ethyl3-(3-dimethylaminopropyl)-carbodiimide (EDC), N-hydroxysuccinimide (NHS), 4-morpholinoethanesulfonic acid (MES), glutaraldehyde, paraformaldehyde, and Hoechst 33343 were purchased from Sigma-Aldrich. Collagenase I, Dulbecco's Modified Eagle Medium (DMEM), and L-glutamine were obtained from Bioidea. FITC-conjugated anti-CD44, PE-conjugated anti-CD106, and CD 34 and PerCep-conjugated anti-CD105 antibodies were supplied by Abcam (Cambridge, UK). Also, fetal bovine serum (FBS), trypsin, and penicillin/streptomycin were purchased from Gibco by Life Technologies. Hexamethyldisilazane (HMDS), 3-(4, 5-dimethylthiazol-2-yl)-2, 5-diphenyltetrazolium bromide) tetrazolium (MTT), and ethanol and dimethyl sulfoxide were bought from Merck.

2.2. Collagen Extraction. Collagen type I was extracted from rat's tail tendon as previously reported [29]. Briefly, rats' tails were sterilized in $70 \%$ ethanol. Then, the disinfected tails were skinned and tendons were pulled out and stored in phosphate-buffered saline (PBS). The tendons were delipidized by acetone and isopropanol, each for 5 minutes. Fibers were well stirred in $0.02 \%$ acetic acid for 48 hours at $4^{\circ} \mathrm{C}$. Thereafter, a viscous solution was blended, stored in $-20^{\circ} \mathrm{C}$, and lyophilized (LD Plus Alpha, Germany) for 48 hours to obtain the collagen sponge.

2.3. Electrospinning of Collagen Solution. Collagen was dissolved in HFIP at a concentration of $3 \%, 6 \%$, and $8 \% \mathrm{w} / \mathrm{v}$ overnight while stirring at room temperature until it became homogeneous. The electrospinning setup used in this study consists of a syringe with an inner diameter of $12 \mathrm{~mm}$ and needle gauge size 22 with an inner diameter of $0.4 \mathrm{~mm}$, a disc collector with $20 \mathrm{~cm}$ diameter and rim width of $1 \mathrm{~cm}$ with rotation speed variety, a ground electrode, and a high voltage supply that was capable of generating positive DC voltage up to $30 \mathrm{kV}$. The needle was connected to the high voltage supply. Different concentrations of collagen/HFIP were pumped to the needle with a flow rate of $1 \mathrm{~mL} / \mathrm{h}$, using a syringe pump. The distance between the tip of the needle and the disc collector, which was connected to the ground electrode, was $15 \mathrm{~cm}$. The three different positive voltages of $15 \mathrm{kV}, 20 \mathrm{kV}$, or $25 \mathrm{kV}$ applied to the needle tip were tested. The disc collector rotation speed variation was from 600 to $2500 \mathrm{rpm}$. Glass slides were covered by wrapping plastic stretch film and pasted on the rim of the disc collector. Light microscope (Leica Microsystems, Germany) images were taken to assess the electrospun fiber morphology and diameter. ImageJ software (http://imagej.nih.gov/ij/index. html) was used to estimate the fiber thickness.

The best collagen concentration was used to fabricate multilayered collagen scaffolds. To make the layered oriented scaffold, the rim of the collector was covered by aluminum wrapping foil $(2 \times 2 \mathrm{~cm})$, as a grounded collector, and it was turned $90^{\circ}$ horizontally every 2 hours. As a result, the orientation of the aligned collagen fibers was perpendicular to the collagen fiber orientation in the adjacent layers (Figure 1). Therefore, the scaffold containing four layers of the aligned collagen fibers was fabricated by $6 \%$ collagen, $2500 \mathrm{rpm}$ speed, $15 \mathrm{~cm}$ needle-collector distance, and $20 \mathrm{kV}$ applied voltage condition at ambient temperature. For mechanical testing one-layer oriented collagen scaffolds were electrospun for $8 \mathrm{~h}$ similar to the layered oriented scaffolds.

2.4. Cross-Linking of the Collagen Electrospun Scaffold. Two protocols were run for cross-linking of the collagen electrospun nanofibrous membrane. For the first protocol $(P 1), 5 \mathrm{mM}$ EDC $(\mathrm{pH}=5.5)$ and $2 \mathrm{mM}$ NHS were added to the buffer containing $70 \%$ ethanol and $5 \mathrm{mM}$ MES, and the electrospun scaffold was immersed in the cross-linking solution for $4 \mathrm{~h}$. To inhibit cross-linkers, the scaffold was placed in Na2HPO4 for $30 \mathrm{~min}$ and rinsed with deionized water 3 times, each one for 5 minutes. For the second protocol $(P 2)$, the electrospun scaffold was cross-linked by treatment of a solution consisting of $200 \mathrm{mM}$ NHS and $200 \mathrm{mM}$ EDC in absolute ethanol under mild shaking for 1 


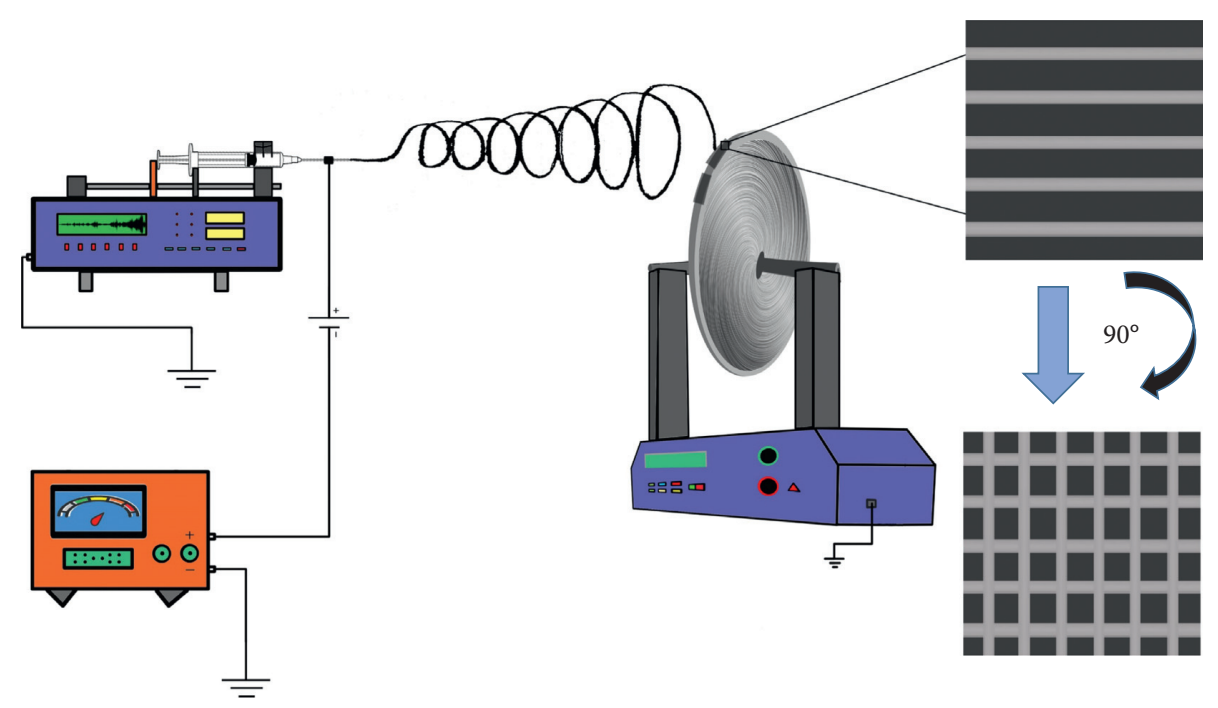

Figure 1: Schematic drawing of the electrospinning setup with a rotating disc collector.

hour at ambient temperature. After aspirating cross-linking solution, nanofiber scaffolds were washed as mentioned above. Then, the dried mats were cut into appropriate pieces for further evaluations.

2.5. Fourier Transform Infrared Spectroscopy (FT-IR) Test. Non-cross-linked as well as cross-linked collagen electrospun scaffold were analyzed, using a FTIR spectrophotometer (Tensor II, Bruker, Germany). FTIR spectra were recorded in the wavelength range of $500-3500 \mathrm{~cm}^{-1}$ with an average of 256 scans at a resolution of $4 \mathrm{~cm}^{-1}$.

2.6. Determination of Protein Release, Degradation, and Porosity. Cross-linked electrospun collagen scaffolds were cut into $0.5 \times 0.5 \mathrm{~cm}$ pieces. The pieces were then incubated in $\mathrm{PBS}$ (PH 7.4) at $37^{\circ} \mathrm{C}$ for days $1,3,7$, and 30 , and protein release from electrospun collagen fibers was measured by NanoDrop UV spectrophotometer (BioTek Laboratories, Inc., USA) at each time point. The samples were also weighted at the mentioned time points after being washed with distilled water and dried using a vacuum.

For degradation test, electrospun collagen scaffolds were weighted and then treated with $0.25 \%$ trypsin in $1 \mathrm{~mL}$ PBS $(\mathrm{pH}=7.4)$ and incubated at $37^{\circ} \mathrm{C}$ under agitation conditions for $0.5,1$, and every one hour up to 6 hours. After the intended time, the scaffolds were washed with deionized water, air-dried and weighed again. The percentage of weight loss was calculated according to the following formula:

$$
\text { weight loss }(\%)=\frac{W_{i}-W_{t}}{W_{t}} \times 100,
$$

where $W_{i}$ is the original weight of nanofibers and $W_{t}$ is the weight of remaining nanofiber scaffolds.

To estimate the porosity, preweighed $\left(\mathrm{W}_{i}\right)$ samples were immersed in absolute ethanol to penetrate into the pores of the entire nanofiber scaffolds. The trapped bubbles were removed by incubating the nanofiber scaffolds in a vacuum chamber at 100 pa for $20 \mathrm{~min}$ and then reweighed $\left(W_{e}\right)$ after wiping off the surface ethanol. The porosity\% was calculated according to the following formula:

$$
\operatorname{porosity}(\%)=\frac{W_{e}-W_{i}}{\rho V_{s}} \times 100
$$

where $\rho$ is the density of ethanol at room temperature $(0.789 \mathrm{mg} / \mathrm{mL})$ and $V_{s}$ is the volume of the swollen scaffold.

2.7. Cell Culture. Normal human adipose tissue-derived mesenchymal stem cells (hAT-MSCs) were isolated from a healthy volunteer undergoing liposuction surgery. In brief, after washing with PBS, the tissues were digested with $0.2 \%$ collagenase I under alternating shaking every $5 \mathrm{~min}$ for $45 \mathrm{~min}$ in $5 \% \mathrm{CO}_{2}$ at $37^{\circ} \mathrm{C}$. The cell suspension was filtered through $40 \mu \mathrm{m}$ cell strainer and then centrifuged at $2000 \mathrm{rpm}$ for $5 \mathrm{~min}$. The cell pellet was cultured in the presence of DMEM supplemented with 10\% FBS, 2 mM L-glutamine, and $1 \%$ penicillin/streptomycin. Media were refreshed every 2 days and the cells were passaged every 10 days. The cells at the $3^{\text {rd }}$ passage were used for culture on the sterilized electrospun scaffolds. The sterilization of the nanofiber scaffolds was performed by immersion in $75 \%$ ethanol twice for $30 \mathrm{~min}$, and after that, they were rinsed with PBS 3 times and soaked in the medium.

To characterize hAT-MSCs, cell surface markers were analyzed by flow cytometry. To do this, the harvested cells were treated with permeabilization medium containing tween 20 in PBS; then, they were exposed to FITC-conjugated anti-CD44, PE-conjugated anti-CD106, and CD 34 and PerCep-conjugated anti-CD105 for 1 hour; and after that, they were fixed with $4 \%$ paraformaldehyde. The cells were analyzed by four-color FACS Calibur flow cytometry machine with Cell Quest Pro software for data acquisition. The data were analyzed by Flow Jo software. 
2.8. Cell Viability and Adhesion Assessment. To evaluate the adhesion property, the $2 \times 10^{3}$ hAT-MSCs were cultured on $5 \times 5 \mathrm{~mm}$ either disinfected scaffolds or collagen-coated culture plate as control. After $1 \mathrm{~h}$, the culture media containing unattached cells were removed. To be sure about the removal of trapped unattached cells, we washed the cellloaded scaffolds with culture medium and this culture medium was added to the previously collected one. The collecting medium was centrifuged and the cell pellets were resuspended in $1 \mathrm{~mL}$ culture medium. The unattached cells were counted by hemocytometer and the number of attached cells was calculated by subtracting the unattached cells from the initial cell number and the value was reported as a percentage.

Moreover, cell viability was measured by MTT assay by culturing the $2 \times 10^{3} \mathrm{hAT}-\mathrm{MSCs} / 5 \times 5 \mathrm{~mm}$ either disinfected scaffolds or collagen-coated culture plate as a positive control for 1, 3, and 7 days. At each point of time, the culture media were replaced with $0.5 \mathrm{mg} / \mathrm{mL}$ MTT prepared in the FBS-free DMEM and incubated at $37^{\circ} \mathrm{C}$ for $4 \mathrm{~h}$. After that, the MTT were replaced with $200 \mu \mathrm{L}$ dimethyl sulfoxide as a solvent of the precipitating formazan crystals for $15 \mathrm{~min}$. The eluted formazan was quantified by measuring the optical density at $570 \mathrm{~nm}$ by a microplate reader (BMG, Labtech). Cell-free DMEM was also used as blank controls to subtract the optical density value of DMEM.

To evaluate the cell distribution on the scaffolds, the same number of cells was cultured on the scaffolds for 7 days, and, then, they were fixed with $4 \%$ paraformaldehyde and stained with $1 \mu \mathrm{g} / \mathrm{mL}$ Hoechst 33343 for $5 \mathrm{~min}$ at room temperature and in the dark. After washing, the samples were observed under a fluorescence microscope with $360 \mathrm{~nm}$ and $460 \mathrm{~nm}$ excitation and emission wavelengths, respectively.

2.9. Scanning Electron Microscopy (SEM). Morphological appearances of both frozen-dried non-cross-linked and frozen-dried cross-linked electrospun collagen fibers were studied by SEM (TESCAN-Vega 3, TESCAN, Czech Republic). The samples were coated with gold by sputter coating for $300 \mathrm{~s}$ using a Q150R- ES sputter coater (Quorum Technologies, London, UK) at an accelerating voltage of $20 \mathrm{kV}$. The scaffolds were prepared for SEM, each layer of the aligned collagen fibers was electrospun for just $10 \mathrm{~min}$ and then the scaffolds were turned $90^{\circ}$ to form the next layer. In this way, thin layers were formed and the underneath layers could be detected by SEM. Orientation and thickness of electrospun collagen fibers were evaluated using ImageJ software.

To assess the cutting edge of the frozen fracture scaffolds, the mats were submerged directly in liquid nitrogen and cut immediately. The mats were dried in a vacuum dryer, and the cleaved edge was prepared for SEM.

To find the cell phenotype and attachment, $18 \times 10^{3}$ hAT-MSCs were seeded on $15 \times 15 \mathrm{~mm}$ scaffolds. Cellloaded scaffolds were fixed by $2.5 \%$ glutaraldehyde for $2 \mathrm{~h}$ at $4^{\circ} \mathrm{C}$ for $20 \mathrm{~min}$. Then, they were dried in increasing gradient concentration of ethanol, each step for $5 \mathrm{~min}$. After the water extraction step, scaffolds were transferred to HMDS and ethanol at ratios of $1: 3,1: 1$, and $3: 1$, respectively, and, finally, the scaffolds were placed in absolute HMDS and HMDS was let to evaporate. Next, dried scaffolds were coated with gold and observed by SEM.

2.10. Confocal Raman Spectroscopy. Four different specimens including non-cross-linked collagen and cross-linked collagen electrospun scaffolds along with cell-loaded crosslinked collagen electrospun scaffold were prepared for Raman confocal microscopy. Cells at the density of $2 \times 10^{3}$ were grown on the scaffolds for 10 days. The Raman spectra of different scaffolds were compared with those in naïve rat intervertebral disc. Bonds and bending vibration of biological molecule sat wavelength range of $500-2000 \mathrm{~cm}^{-1}$ with an average of 200 scans were detected using a Raman spectrophotometer (Lab Ram HR, Horiba, Japan) with a $532 \mathrm{~nm}$ laser beam, 600 grooves/mm grating, and $100 \mathrm{x}$ visible objective, $\mathrm{NA}=0.9 \mathrm{WD}=0.21 \mathrm{~mm}$. To evaluate glycosaminoglycans and hydroxyproline distribution, Raman images were produced at $856 \mathrm{~cm}^{-1}$ (blue) and $1062 \mathrm{~cm}^{-1}$ (red), respectively [30].

2.11. Mechanical Property Test. Samples were cut into rectangular strips, $5 \mathrm{~mm} \times 13 \mathrm{~mm}$, with a thickness of $0.65 \mathrm{~mm}$. Prior to testing, cross-linked one layer along with multilayered oriented nanofiber collagen scaffolds were immersed in PBS. In order to prevent slipping out of scaffolds from the clamp, a holder was made from a rectangular paper that supported each side of the scaffold, and then the supported nanofiber collagen scaffolds were carefully fixed with the clamps. The mechanical properties of the scaffolds were evaluated by Instron 3342 mechanical testing machine using across speed of $5 \mathrm{~mm} / \mathrm{min}$ and an initial gauge length of $5 \mathrm{~mm}$ at room temperature. Measurement of force $(\mathrm{N})$, ultimate tensile stress $(\mathrm{MPa})$, extension $(\mathrm{mm})$, elastic modulus ( $\mathrm{MPa}$ ), and elongation (\%) at break were assessed. Mechanical properties of the nanofiber collagen scaffolds were determined from the stress-strain curves.

2.12. Statistical Analyses. All statistical analyses were performed using one way-ANOVA and Tukey's post hoc test by SPSS 15.0. $P<0.05$ was considered significant. The graphs were plotted using GraphPad Prism software (GraphPad Prism, v.6.01) and data were shown as mean \pm S.D. All experiments were done in triplicate.

\section{Results and Discussion}

3.1. Alignment Parameters. Align collagen, as a natural biomaterial, has many applications in regenerative medicine. As collagen concentration influenced electrospun fiber features, we tested three different collagen concentrations. The light microscopy revealed that electrospinning for $2 \mathrm{~min}$ produced bead-free nanofibers with uniform diameters along their entire length regardless of collagen concentrations (Figure 2). Although 3\% collagen could electrospin 
$15 \mathrm{kV}$
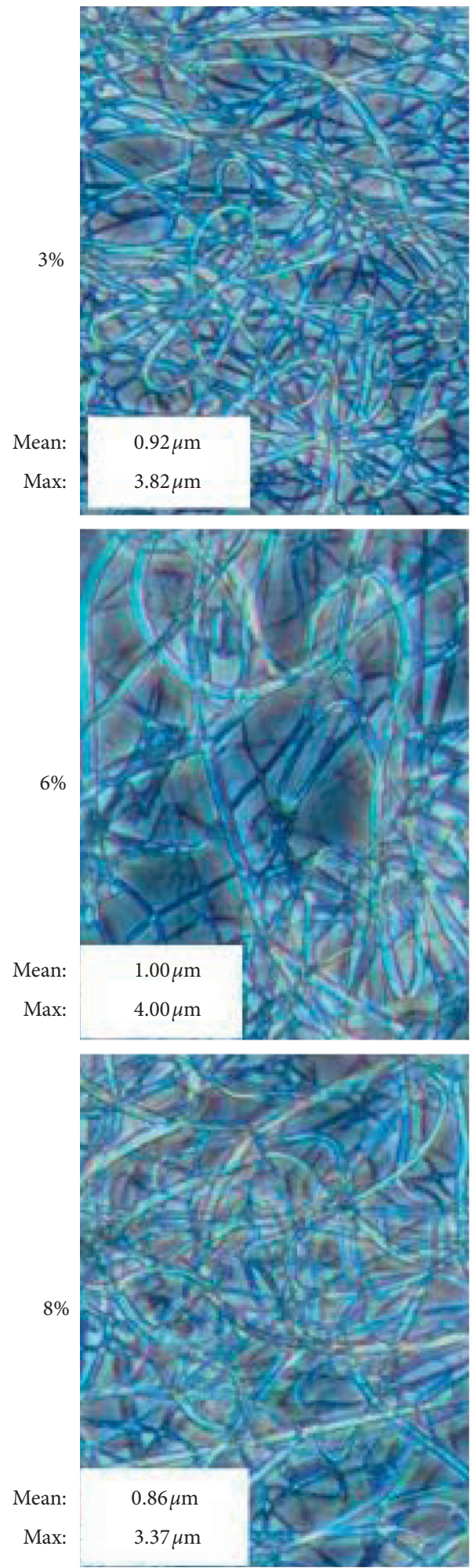

$20 \mathrm{kV}$
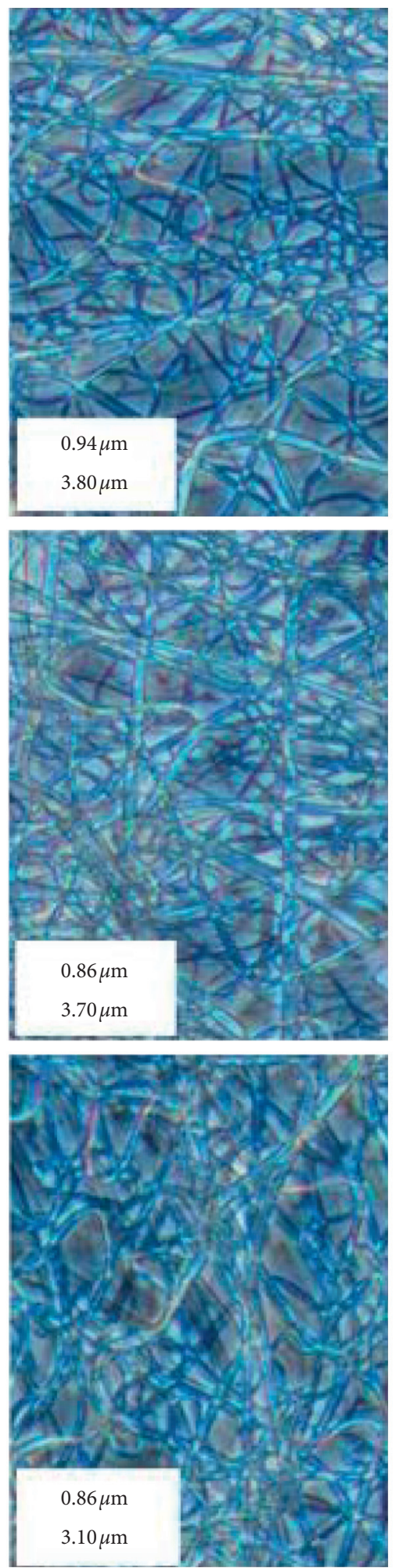

$25 \mathrm{kV}$
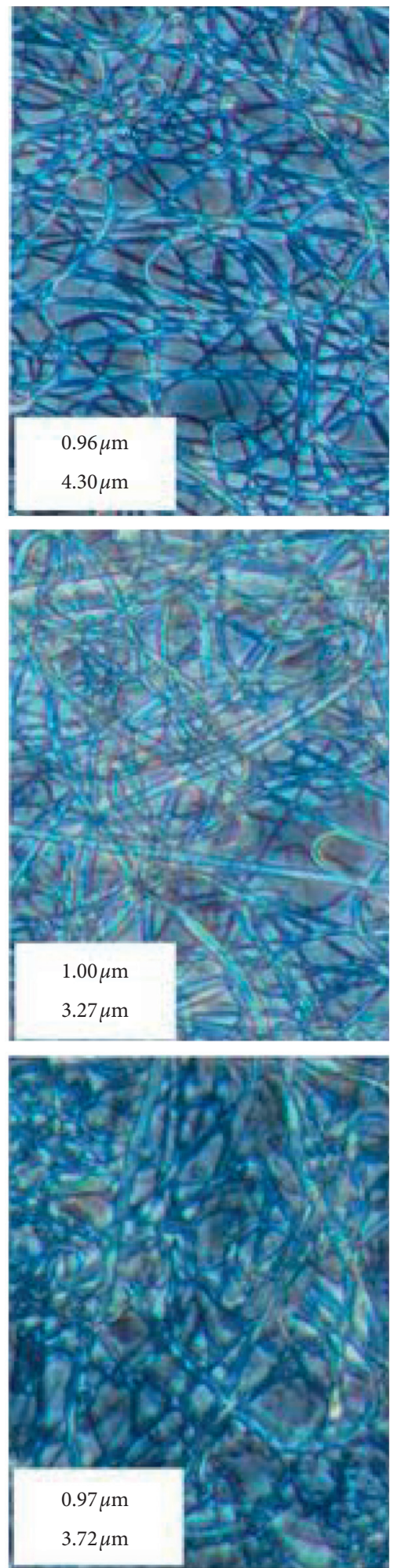

FIGURE 2: Light microscopy images of different concentrations of collagen dissolved in HFIP to prepare 3, 6, and 8\% w/v polymer solutions after electrospinning under different voltages of $15-25 \mathrm{kV}$.

properly, after a while, the collagen electrosprayed, and, as a result, some holes appeared on the target. In the next step, $6 \%$ collagen was electrospun at different voltages, $15 \mathrm{kV}$,
$20 \mathrm{kV}$, and $25 \mathrm{kV}$. As electrospinning of $8 \%$ collagen at different voltages interrupted due to high density, the best result was achieved by $6 \%$ collagen. Therefore, the 
concentration of $6 \%$, voltage of $20 \mathrm{kV}$ with $2500 \mathrm{rpm}$ of disc rotation speed, and the $15 \mathrm{~cm}$ distance were chosen for further experiment. Although reports suggested high concentrations of polymers for align electrospinning, the degree of alignment also depends on the collecting speed/geometry of the collectors as well. Higher speed of collector makes a higher degree of orientation and as a result more efficient and applicable nanofiber mats $[5,31]$. In a study, researchers used $8.4 \%$ type I collagen in HFIP to make an electrospun mat for cell seeding [32]. In another study, 6\% human placental derived collagen in the same solvent was used to align electrospinning [20]. Choosing the right collagen concentration for fabricating align fibers depends on both collagen source and type [33]. In the current study, rat tailderived collagen in HFIP was used and 6\% collagen was found to be the best concentration for fabricating align fiber mat. Higher concentration of the pure collagen solution has been proposed to produce nanofibers with a larger diameter [8]. In contrast, our light microscopy study revealed no statistically significant changes in the mean value of nanofiber thickness prepared with different collagen concentrations collected on glass microscope slide. A previous study demonstrated that the average collagen fiber diameter highly increased at high concentrations from $8 \%$ to $9 \%$. Besides, they used a wire-grid ground collector instead of wrapping plastic stretch film on glass slide [31]. It was suggested that not only the type of collectors but also the type of surface covering of the collector such as aluminum foil, glass slides, or Petri dishes can influence the pattern and quality of the electrospun fiber structure [34, 35].

The cross-linking process improved the scaffold quality since non-cross-linked electrospun collagen fibers were brittle and dissolved after immersion in PBS. The crosslinked scaffolds through $P 1$ were invisible and transparent, and it was very difficult to detach them from aluminum foil for further processing. Although the scaffolds cross-linked by $P 2$ were transparence, it could be still observed in a liquid environment with the naked eye and separated from aluminum foil easily. In organs such as the cornea, the parallel arrangement of collagen fibers in each individual lamella is one of the reasons for transparency [22].

The SEM images confirm that the 3D multilamellar scaffold was successfully spun (Figure 3 ). ImageJ analysis revealed that the goodness of oriented collagen fibers was $96.5 \% \pm 0.8$. It indicated that the fibers were directed parallel in each layer. The goodness close to 1 indicates more oriented fibers. In the previous studies, researchers tried to get oriented fibers using some techniques like wired drum collector [13]. Magnetic field-assisted electrospinning was also performed using a wire drum collector to fabricate oriented fibers. However, the money can be saved if oriented fibers will be obtained by routine electrospinning tools and only a simple disc collector. In this study, we fabricated an oriented fiber-containing construct using a high-speed rotating disc collector $(2500 \mathrm{rpm})$ in order to lower the costs.

The ImageJ analysis showed that the mean value of fiber thickness was $0.14 \pm 0.4 \mu \mathrm{m}$ and the maximum thickness was $0.5 \pm 0.08 \mu \mathrm{m}$. Both cross-linked and non-cross-linked multilayered scaffolds revealed aligned uniaxially oriented electrospun fibers in each layer. After cross-linking, the morphology of the fibers remained intact. The orientation of the aligned fibers in each layer showed an angle of about $90^{\circ}$ with respect to the fibers in the adjacent lamella. Freeze fracture of cross-linked multilayered collagen fibers also exhibited that the layers were continuous without any gap and compression in the fracture area. The nature of many tissues like cornea and AF which consist of oriented, lamellar, and submicron fibers has lead researchers to find a way to construct biomimicry scaffold using techniques such as electrospinning [4, 22]. Several studies have pointed to making oriented fibers and even lamellar scaffolds using different polymers [4, 16-18]. Kang et al. fabricated multilamellar scaffold with a combination of aligned electrospinning of PCL and fused-deposit-modeling (FDM) microfibers [36]. However, to our knowledge, none of the studies focused on fabricating crossed-layer-by-layer collagen scaffold which is a natural polymer. Since type I collagen has a unique biological function and physiochemical properties such as poor immunogenicity and excellent biocompatibility, it is superior for recapitulating the ultrastructure of native fibers compared to the other types of polymers and highly desirable for medical applications. Native type I collagen diameter is between 30 and $300 \mathrm{~nm}$, while electrospun pure collagen nanofiber thickness usually was 50 to $1000 \mathrm{~nm}$. The diameter of electrospun fibers is influenced by collagen concentrations $[8,33]$. Our fabricated collagen mat contains fibers with an average thickness of about $140 \mathrm{~nm}$ which is in the range of naive collagen fibers.

Ultrastructure analysis of cultured cells on aligned electrospun fibers showed that hAT-MSCs had some thin filopodia that attached or penetrated under the collagen fibers. The cell processes seem to be aligned with parallel collagen fibers (Figure 4). It has been suggested that oriented collagen nanofibers regulate cell activity [12]. Despite the lack of clarity in SEM images after cross-linking, fibrillar morphology of collagen electrospun fibers was preserved after immersion in culture media.

3.2. FTIR Test. The IR spectroscopic method has been used to investigate the cross-link of collagen. The comparison of the spectra of uncross- and cross-linked collagen electrospun nanofibers (Figure 5) showed a newly formed ester bond at $1778 \mathrm{~cm}^{-1}$ that indicates the formation of new bands after cross-link. Due to cross-linking, increasing absorbance around 1240 and $1550 \mathrm{~cm}^{-1}$ (C-N stretching vibration/N-H bending vibration) showed more amide II and III bonds. Also, $-\mathrm{CH}_{2}$ bending vibrations were observed at a wavenumber of 1240 and $1370,1430 \mathrm{~cm}^{-1}$ in cross-linked collagen nanofibers that corresponded to the amino acid side chain of collagen. $\mathrm{N}-\mathrm{H}$ bending vibrations and $\mathrm{C}=\mathrm{O}$ stretching vibrations (amide I) of polypeptide chains represented at $1646 \mathrm{~cm}^{-1}$. Besides, decreased transmittance at $1730 \mathrm{~cm}^{-1}, 2930 \mathrm{~cm}^{-1}$, and $3330 \mathrm{~cm}^{-1}$ can be ascribed to $\mathrm{C}=\mathrm{O}$ stretching vibrations of ester and acidic groups, asymmetric $\mathrm{C}-\mathrm{H}$ stretching vibration due to amide $\mathrm{B}$ bands, and $\mathrm{N}-\mathrm{H}$ stretching vibrations for amide $\mathrm{A}$, respectively [37]. 


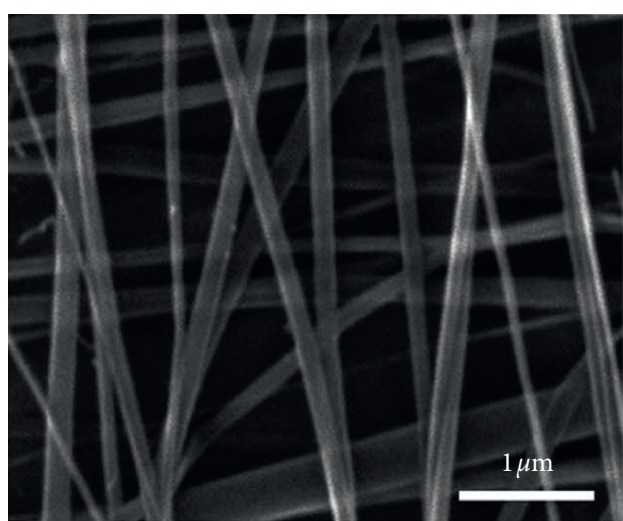

(a)

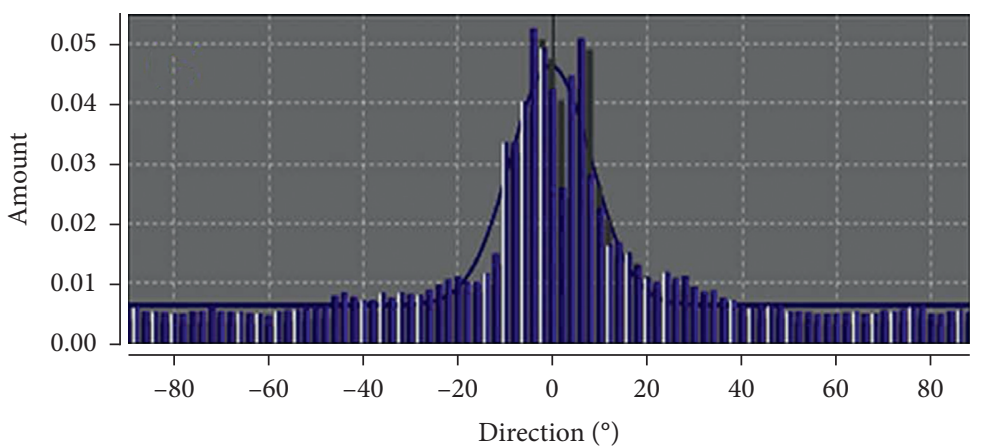

】 Montage-1

- Montage-1

(c)

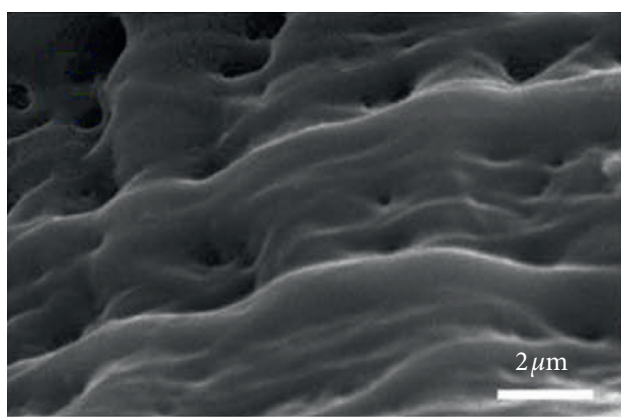

(e)

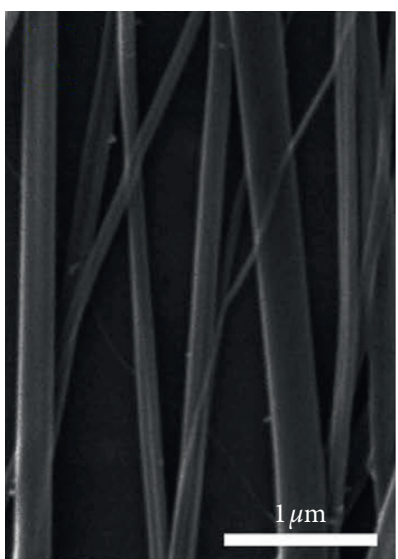

(b)

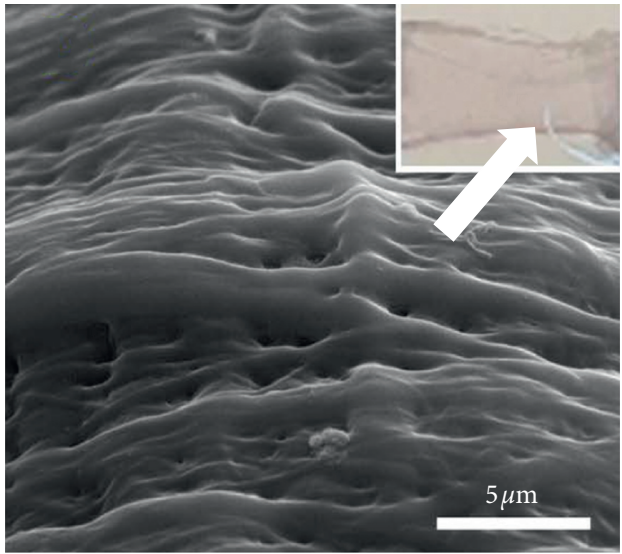

(d)

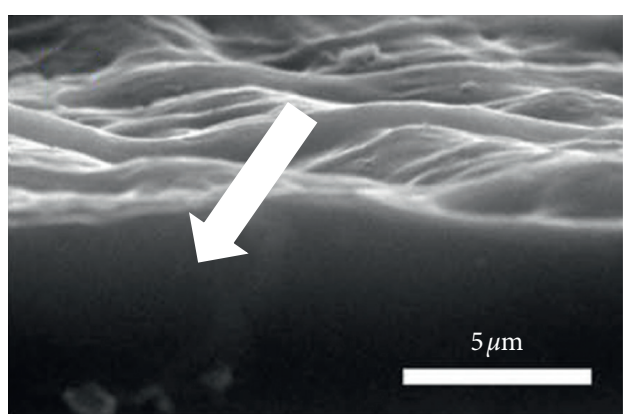

(f)

FIGURE 3: Scanning electron micrographs of electrospun collagen fibers before and after cross-linking. (a) The orientation of the aligned fibers in each layer compared to the fibers in adjacent lamella. (b) The morphology of the parallel arrangement of collagen fibers in noncross-linked scaffold. (c) Fiber orientation histogram. (d and e) Cross-linked multilayered scaffolds with aligned uniaxially oriented electrospun fibers in each layer. Black arrow shows the transparency of the scaffold. (f) Freeze fracture of cross-linked multilayered collagen fibers (white arrow).

According to the increased and newly absorption peaks that were observed in FTIR spectra of cross-linked collagen nanofibers compared to extracted collagen, the formation of new bonds could be confirmed. It was recorded that crosslinking with EDC led to an increase in collagen mechanical strength and stability in aqueous solutions and a decrease in degradation rate; however, the scaffolds lost porous structure [28]. Cross-linking of collagen using equal molar ratios of EDC to NHS has been reported to elevate mechanical strength compared to double molar ratios of EDC to NHS $[25,27]$. We also used equal molar ratios of EDC to NHS to increase mechanical strength. Despite porosity preservation, the pore size declined after cross-linking. The decline in pore size, which is indicated by SEM micrograph images, may be due to fiber swelling [25].

3.3. Protein Release, Degradation, and Porosity Test. After incubation in PBS for 1 day, collagen electrospun scaffolds 


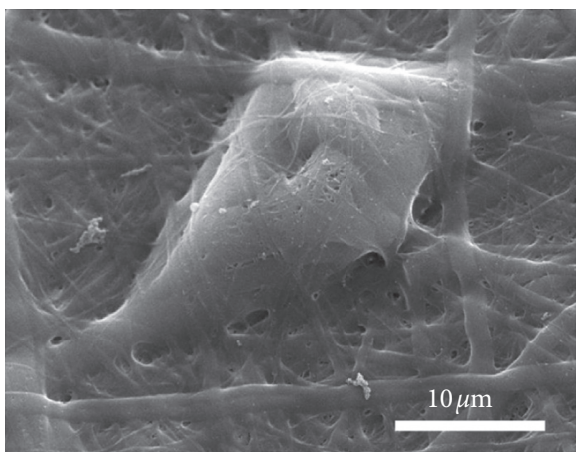

(a)

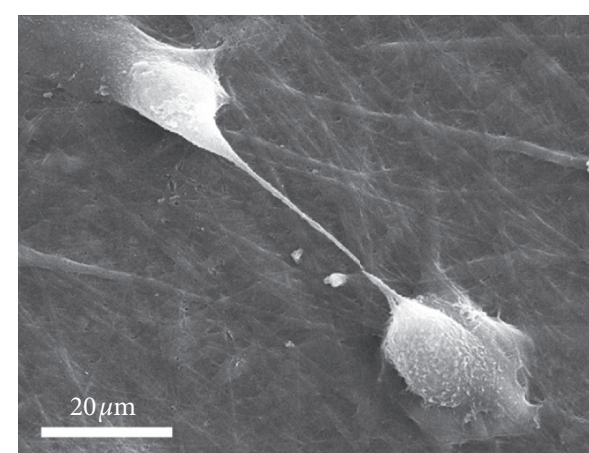

(b)

FIGURE 4: Scanning electron microscope images of human adipose tissue-derived mesenchymal stem cells (hAT-MSCs) cultured on crosslinked collagen electrospun nanofibers for 10 days.

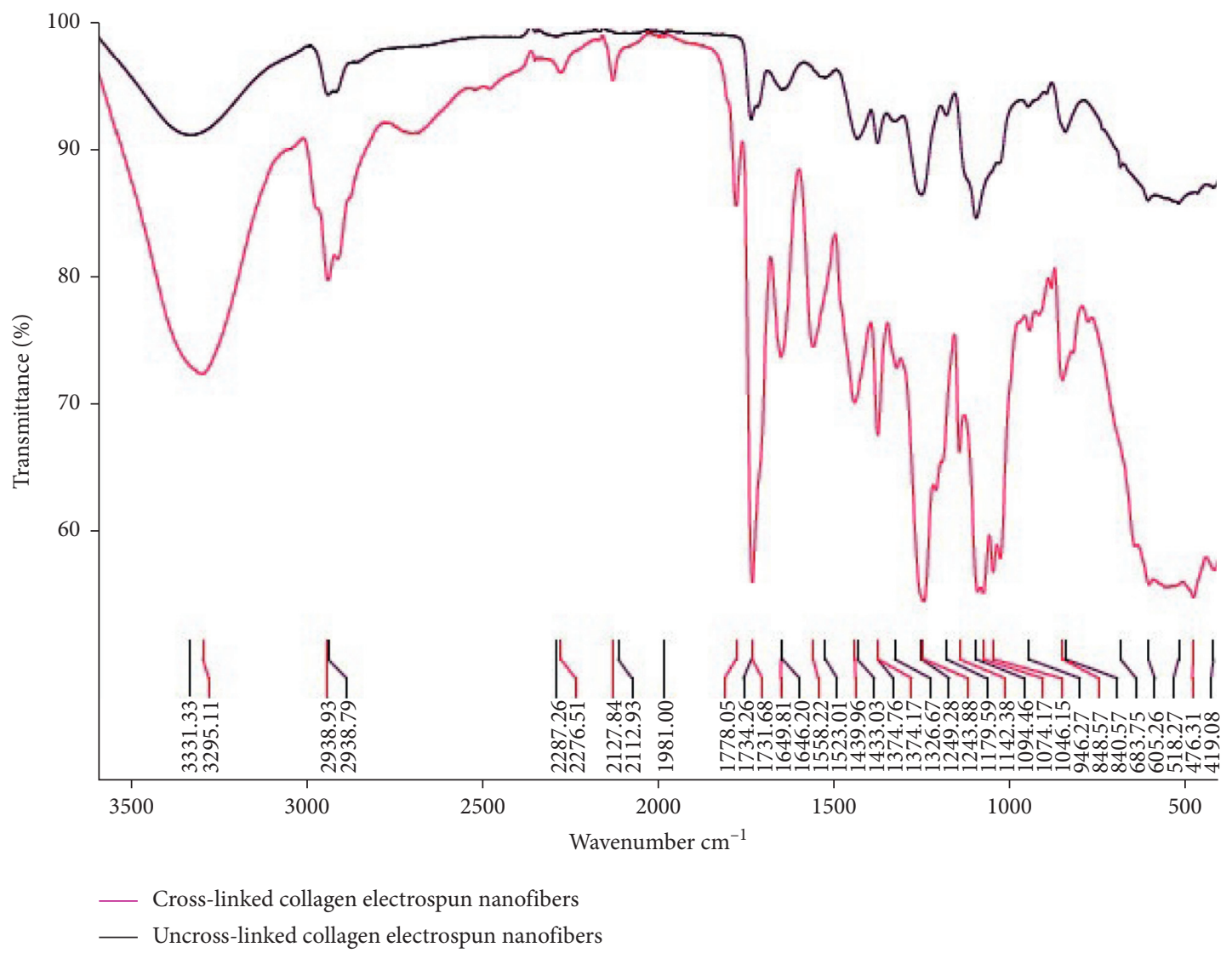

FIGURE 5: FTIR spectra of uncross-linked and cross-linked collagen electrospun nanofibers.

released $0.03 \pm 0.67 \mathrm{mg} / \mathrm{mL}$ of protein; however, on days 3,5 , 7 , and 30 , protein release ceased from the scaffolds, while the scaffold weights $(0.046 \mathrm{mg})$ remained constant at all point of times and retained their integrity.

After 30 minutes of incubation of collagen scaffolds in trypsin solution (Figure 6(a)), 40\% of weight loss was observed. The degree of weight loss was increased to $55 \%$ and $60 \%$ after 1 - and 2-hour trypsin treatment, respectively.
However, weights of scaffolds remained constant after treatment for 3, 4, 5, and 6 hours. Fast degradation is not desirable for tissue engineering applications [38].

Also, the porosity of collagen electrospun scaffolds was calculated as $60 \% \pm 1.4 \%$. It has been well documented that scaffolds created using electrospinning show high surface area to volume ratio, high porosity, and high pore interconnectivity which are essential for cell adhesion, migration, and 


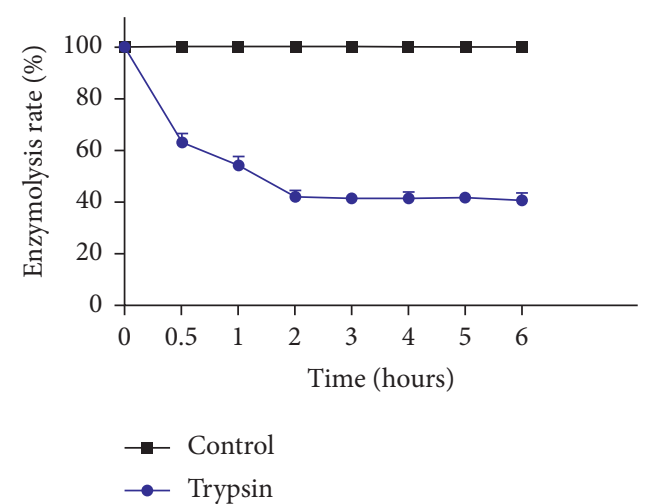

(a)

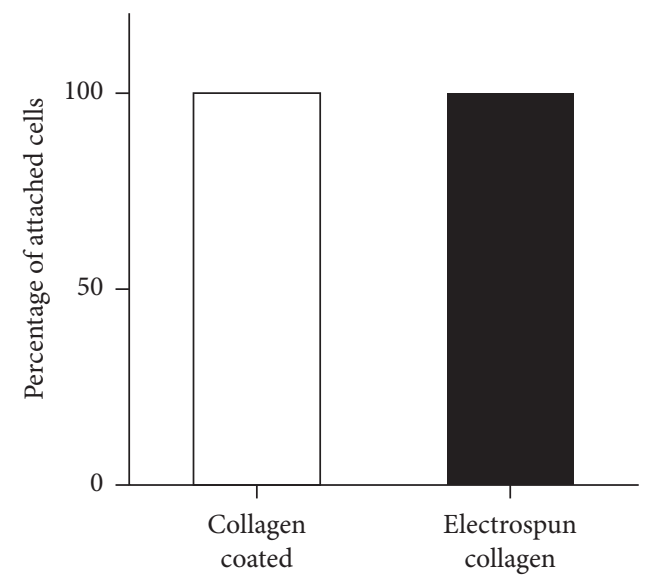

(c)

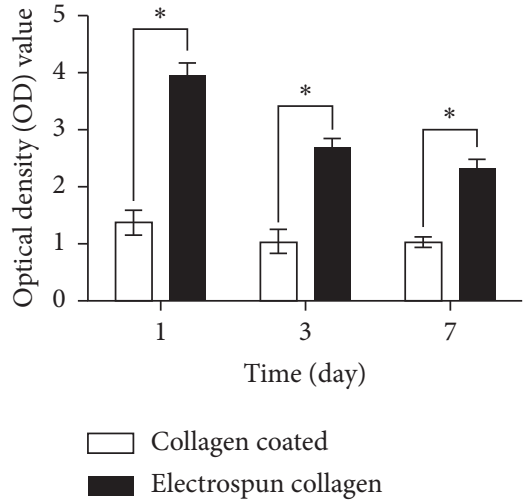

(b)

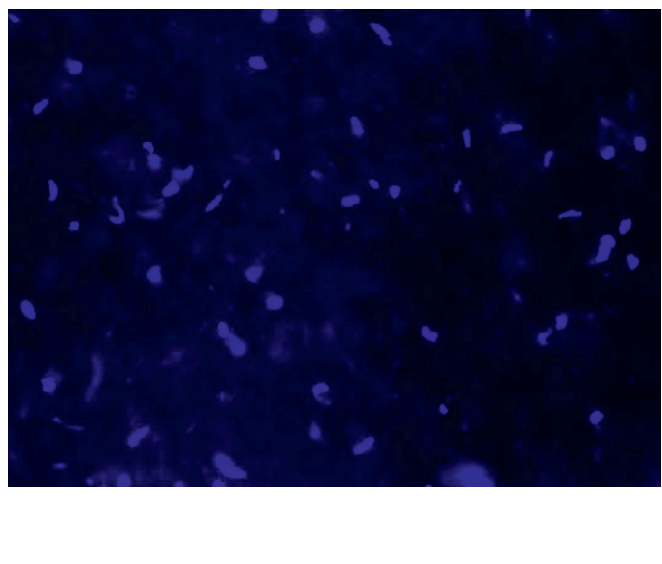

(d)

Figure 6: (a) Degradation test of electrospun collagen scaffolds treated with $0.25 \%$ trypsin by calculating the percentage of weight loss. Phosphate buffered saline alone was used as a control. (b) Cytotoxicity assay of human adipose tissue-derived mesenchymal stem cells cultured on cross-linked collagen electrospun nanofibers or collagen-coated culture dishes as a control group. (c) Cell adhesion test of human adipose tissue-derived mesenchymal stem cells (hAT-MSCs) seeded on cross-linked collagen electrospun nanofibers or collagencoated culture dishes as a control group. (d) The live cells stained with Hoechst to show the distribution and adhesion of hAT-MSCs to scaffolds. Bar represents mean $\pm \mathrm{SD}\left({ }^{*} P<0.05, N=3\right)$.

proliferation [21]. As the porosity of organs such as decellularized cornea was recorded as $51.1 \%$ [39], it seems that this construct is appropriate for tissue engineering of such an organ.

3.4. Cell Viability and Adhesion Tests. Cell viability was evaluated by MTT test (Figure 6(b)). The MTT results demonstrated a significant increase in cell population seeded on scaffolds compared to coated collagen culture plates as control from day 1 till day 7 ( $P<0.0001$ for all days). However, at 3 and 7 days after culturing, viable cells were less than day 1. Both Hoechst and SEM tests confirmed the presence of viability of cells. Improved capacity of the proliferation rate of the hAT-MSCs could be due to the presence of collagen in the aligned nanofibrous scaffold with higher area ratio and biocompatibility. Previous studies showed that aligned nanofibrous scaffolds led to an increase in cell proliferation and migration rates that lead to tissue regeneration [14].
The adhesion test revealed that $99 \%$ of cells were attached to both electrospun scaffold and thermogelated collagen as a conventional 2D substrate after $1 \mathrm{~h}$. Hoechst staining also confirmed the presence of hAT-MSCs adhering to the electrospun collagen fibers (Figures 6(c) and 6(d)). The staining also revealed some degree of cell migration deep into the scaffolds. These tests along with SEM images confirmed cell attachment, migration, and intercellular junction of hAT-MSCs could be evidence for proper physical and chemical construct to mimic natural microenvironment and presenting extracellular signals that support biological function of the cultured cells [14]. Our findings were consistent with the studies indicating that electrospun collagen fiber could facilitate cell migration.

3.5. Confocal Raman Spectroscopy. Confocal Raman spectroscopy was applied for collagen and cross-linked scaffold along with naive intervertebral disc for detailed evaluation of the ECM produced by cultured cells (Figure 7). General trends of spectra for cell-free collagen with/without 


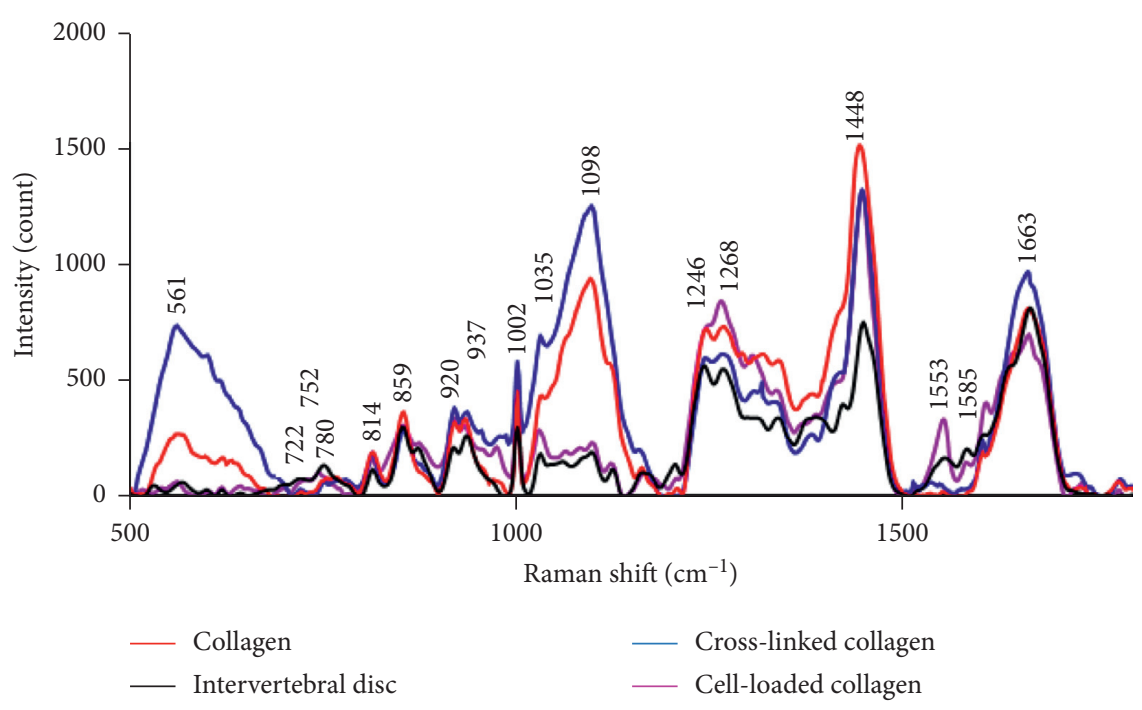

Figure 7: Comparing Raman spectra of four different specimens including, non-cross-linked collagen, cross-linked collagen electrospun scaffolds, cell-loaded cross-linked collagen electrospun scaffold, along with naive intervertebral disc for content.
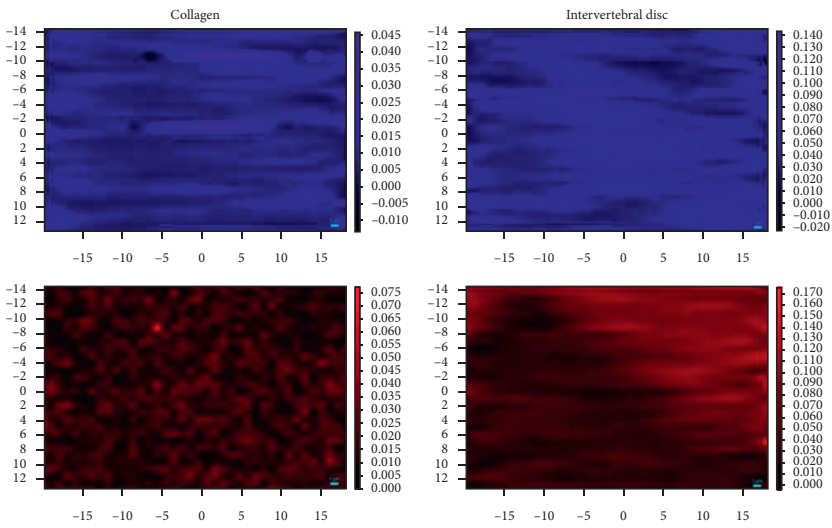
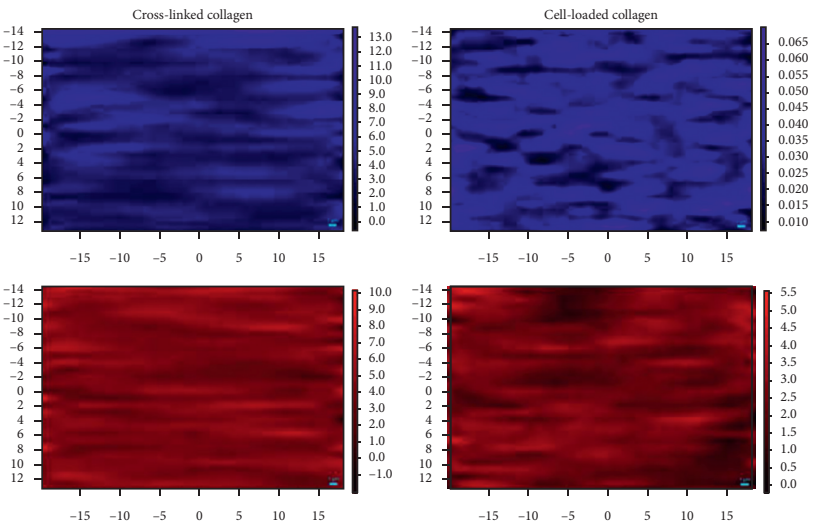

FiguRE 8: Raman confocal maps of four different specimens showed the distribution of glycosaminoglycans (blue) and hydroxyproline (red). The images display close distribution of glycosaminoglycans and hydroxyproline at $856 \mathrm{~cm}^{-1}$ and $1062 \mathrm{~cm}^{-1}$, respectively, in cellloaded cross-linked collagen electrospun scaffold and naive intervertebral disc.

cross-link are closely similar. After culturing the cells on the cross-linked collagen scaffolds, the general trends were close to the intact disc. In spite of minor differences, the data showed that between $500 \mathrm{~cm}^{-1}-960 \mathrm{~cm}^{-1}$ and $990-1200 \mathrm{~cm}^{-1}$, the Raman spectra obtained from cellloaded scaffolds accommodate to the spectra from the intact disc. The trend of the spectra from all the scaffolds was in close vicinity to each other between $700 \mathrm{~cm}^{-1}$, $1000 \mathrm{~cm}^{-1}$, and $1200 \mathrm{~cm}^{-1}$ to $1800 \mathrm{~cm}^{-1}$, except at $1268 \mathrm{~cm}^{-1}$ and $1553 \mathrm{~cm}^{-1}$ that the Raman intensity increased for the cell-loaded scaffolds and intact disc. These spectra were attributed to the typical DNA band and =C$\mathrm{H}$ in phospholipids $[40,41]$. Both of these components are present in the cells, which confirms the presence of cells in the scaffolds. A peak at $561 \mathrm{~cm}^{-1}$ was attributed to $\mathrm{O}-\mathrm{P}-\mathrm{O}$ bending mode $\mathrm{v}$ [42]. Vibrations at $752 \mathrm{~cm}^{-1}$ and $780 \mathrm{~cm}^{-1}$ were assigned to the DNA and uracil-based ring breathing mode, respectively $[43,44]$. These bonds represent the cell nuclei and the intensity was the same in both intact disc and cell-loaded scaffolds. Bands at $859 \mathrm{~cm}^{-1}, 920 \mathrm{~cm}^{-1}, 1002 \mathrm{~cm}^{-1}$, and $1035 \mathrm{~cm}^{-1}$ were assigned for collagen and amino acid, such as tyrosine and phenylalanine $[30,45]$. It seems that the electrospun collagen scaffold could support the cells to produce the same ECM constitutions as intact annulus fibrosus ECM. Raman spectra mapping in Figure 8 also confirmed close distribution patterns of glycosaminoglycans and hydroxyproline in cell-loaded cross-linked collagen electrospun scaffold and naive intervertebral disc.

3.6. Mechanical Properties. As shown in the stress-strain curve (Figure 9), the mats that were composed of crossed oriented fibers could tolerate significant tensile strength with an average of $0.78 \mathrm{MPa}$ in comparison with one-directionoriented fibers with an average of $0.482 \mathrm{MPa}(P=0.002)$. Also, crossed oriented fibers had an average strain at break of $86.6 \%$, while in one-direction fiber mats, the average of 


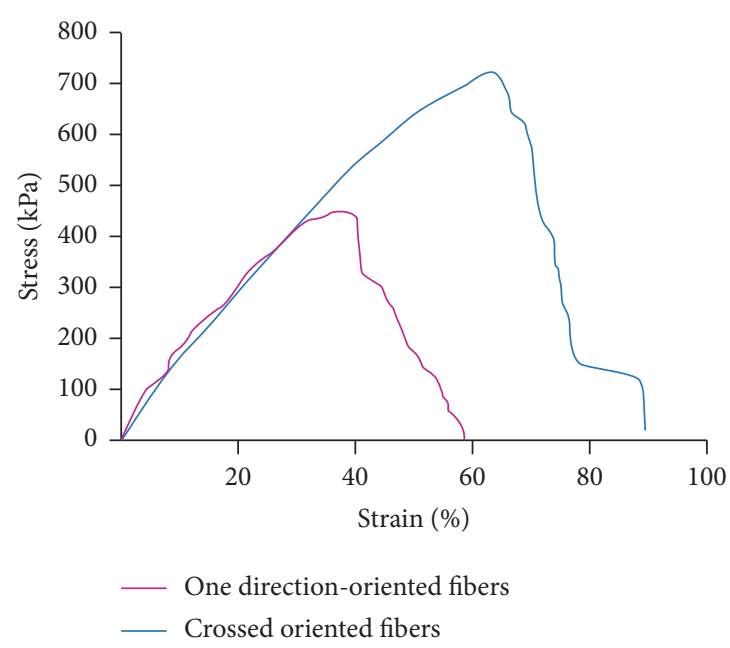

(a)

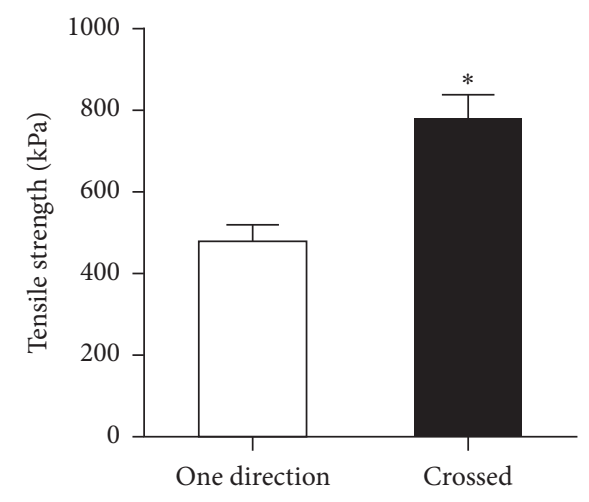

(c)

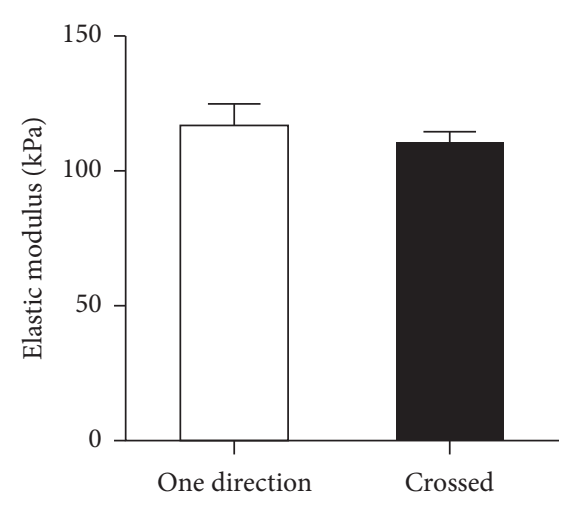

(b)

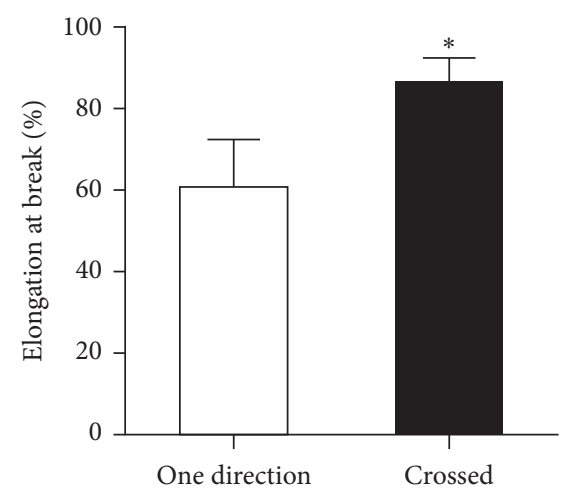

(d)

FiguRE 9: Mechanical properties of cross-linked electrospun collagen nanofibers were assessed for one-direction-oriented fibers and crossed oriented fibers. (a) Representative tensile stress-strain curves, (b) tensile strength at break, (c) elastic modulus, and (d) elongation at break. Data are expressed as mean $\pm \mathrm{SD}\left(N=3,{ }^{*} \mathrm{P}<0.05\right)$.

breaking elongation decreased to $61 \%(P=0.02)$. Nonetheless, the mechanical analysis revealed no significant differences in compressive elastic modulus between aligned and random fibers (the average $0.115 \mathrm{MPa}$ and $0.120 \mathrm{MPa}$, respectively; $P=0.2$ ).

Collagen is responsible for the strength of a tissue. Mechanical property test was run in wet scaffold condition because previous studies have shown that collagen fibers are hard and brittle, which break before the yield point. On the other hand, some studies have shown that when collagen fibers are being tested in wet conditions, they show poor mechanical properties $[23,24]$. In addition to collagen, other polymers like chitosan and hydrogels show less mechanical properties in wet conditions compared to their dry conditions [46, 47]. Other studies compared mechanical properties of nonoriented and oriented PCL fibers in wet conditions, and as a result, oriented fibers showed better resistance [11]. In this study, we confirmed the superior mechanical properties of crossed-layer by layer mats compared to one-direction-oriented fiber mats in wet conditions.

\section{Conclusions}

Our study showed that fabricated multilayered collagen scaffolds can help to retain the integrity and morphology of fibers, support loaded cells for attachment and growth, and reinforce mechanical properties. Overall, this study introduces a cost-benefit way to produce oriented fibers, by concentrating on the rotation speed of the collector, which does not need any other device like the wired drum collector to orient the fibers. The following method can be considered as a promising procedure for tissue engineering and regenerative medicine applications of tissues made of parallel or crossed lamella.

\section{Data Availability}

No data were used to support this study.

\section{Conflicts of Interest}

All authors declare no conflicts of interest. 


\section{Acknowledgments}

This study was conducted at the Laboratory for Stem Cell Research in the Anatomy Department affiliated to Shiraz University of Medical Sciences, Shiraz, Iran. Hereby, the authors would like to present their sincere thanks to Ms. Salmannezhad and Ms. Sani for their technical assistance. The authors wish to thank Mr. H. Argasi at the Research Consultation Center (RCC) of Shiraz University of Medical Sciences for his invaluable assistance in editing this manuscript. The project was assigned as Grant number 96-14988 in the office of the Vice-Chancellor of Research Affairs, Shiraz University of Medical Sciences.

\section{References}

[1] T. Subbiah, G. S. Bhat, R. W. Tock, S. Parameswaran, and S. S. Ramkumar, "Electrospinning of nanofibers," Journal of Applied Polymer Science, vol. 96, no. 2, pp. 557-569, 2005.

[2] Z.-M. Huang, Y.-Z. Zhang, M. Kotaki, and S. Ramakrishna, "A review on polymer nanofibers by electrospinning and their applications in nanocomposites," Composites Science and Technology, vol. 63, no. 15, pp. 2223-2253, 2003.

[3] L. Buttafoco, N. G. Kolkman, P. Engbers-Buijtenhuijs et al., "Electrospinning of collagen and elastin for tissue engineering applications," Biomaterials, vol. 27, no. 5, pp. 724-734, 2006.

[4] N. Wismer, S. Grad, G. Fortunato, S. J. Ferguson, M. Alini, and D. Eglin, "Biodegradable electrospun scaffolds for annulus fibrosus tissue engineering: effect of scaffold structure and composition on annulus fibrosus cells in vitro," Tissue Engineering. Part A, vol. 20, no. 3-4, pp. 672-682, 2014.

[5] X. Shi, W. Zhou, D. Ma et al., "Electrospinning of nanofibers and their applications for energy devices," Journal of Nanomaterials, vol. 2015, Article ID 140716, 20 pages, 2015.

[6] M. S. Khil, H. Y. Kim, M. S. Kim, S. Y. Park, and D.-R. Lee, "Nanofibrous mats of poly (trimethylene terephthalate) via electrospinning," Polymer, vol. 45, no. 1, pp. 295-301, 2004.

[7] S. Li and X.-H. Yang, "Fabrication and characterization of electrospun wool keratin/poly (vinyl alcohol) blend nanofibers," Advances in Materials Science and Engineering, vol. 2014, Article ID 163678, 7 pages, 2014.

[8] Y.-R. V. Shih, C.-N. Chen, S.-W. Tsai, Y. J. Wang, and O. K. Lee, "Growth of mesenchymal stem cells on electrospun type I collagen nanofibers," Stem Cells, vol. 24, no. 11, pp. 2391-2397, 2006.

[9] I. J. H. Barrientos, E. Paladino, P. Szabo et al., "Electrospun collagen-based nanofibres: a sustainable material for improved antibiotic utilisation in tissue engineering applications," International Journal of Pharmaceutics, vol. 531, no. 1, pp. 67-79, 2017.

[10] J. Walser and S. J. Ferguson, "Oriented nanofibrous membranes for tissue engineering applications: electrospinning with secondary field control," Journal of the Mechanical Behavior of Biomedical Materials, vol. 58, pp. 188-198, 2016.

[11] H. H. Ahvaz, H. Mobasheri, B. Bakhshandeh et al., "Mechanical characteristics of electrospun aligned PCL/PLLA nanofibrous scaffolds conduct cell differentiation in human bladder tissue engineering," Journal of Nanoscience and Nanotechnology, vol. 13, no. 7, pp. 4736-4743, 2013.

[12] J. Xue, T. Wu, and Y. Xia, "Perspective: aligned arrays of electrospun nanofibers for directing cell migration," $A P L$ Materials, vol. 6, no. 12, Article ID 120902, 2018.
[13] M.-C. Chen, Y.-C. Sun, and Y.-H. Chen, "Electrically conductive nanofibers with highly oriented structures and their potential application in skeletal muscle tissue engineering," Acta Biomaterialia, vol. 9, no. 3, pp. 5562-5572, 2013.

[14] S. Razavi, S. Karbasi, M. Morshed, H. Z. Esfahani, M. Golozar, and S. Vaezifar, "Cell attachment and proliferation of human adipose-derived stem cells on PLGA/chitosan electrospun nano-biocomposite," Cell Journal (Yakhteh), vol. 17, no. 3, p. 429, 2015.

[15] C. Liu, C. Zhu, J. Li et al., "The effect of the fibre orientation of electrospun scaffolds on the matrix production of rabbit annulus fibrosus-derived stem cells," Bone Research, vol. 3, Article ID 15012, 2015.

[16] L. Yu, Z. Shao, L. Xu, and M. Wang, "High throughput preparation of aligned nanofibers using an improved bubbleelectrospinning," Polymers, vol. 9, no. 12, p. 658, 2017.

[17] Z. Zhou, K. Liu, C. Lai et al., "Graphitic carbon nanofibers developed from bundles of aligned electrospun polyacrylonitrile nanofibers containing phosphoric acid," Polymer, vol. 51, no. 11, pp. 2360-2367, 2010.

[18] S.-F. Chou and K. A. Woodrow, "Relationships between mechanical properties and drug release from electrospun fibers of PCL and PLGA blends," Journal of the Mechanical Behavior of Biomedical Materials, vol. 65, pp. 724-733, 2017.

[19] J. Baek, S. Sovani, N. E. Glembotski et al., "Repair of avascular meniscus tears with electrospun collagen scaffolds seeded with human cells," Tissue Engineering Part A, vol. 22, no. 5-6, pp. 436-448, 2016.

[20] J. A. Matthews, G. E. Wnek, D. G. Simpson, and G. L. Bowlin, "Electrospinning of collagen nanofibers," Biomacromolecules, vol. 3, no. 2, pp. 232-238, 2002.

[21] I. Bruzauskaite, D. Bironaite, E. Bagdonas, and E. Bernotiene, "Scaffolds and cells for tissue regeneration: different scaffold pore sizes-different cell effects," Cytotechnology, vol. 68, no. 3, pp. 355-369, 2016.

[22] Z. Wu, B. Kong, R. Liu, W. Sun, and S. Mi, "Engineering of corneal tissue through an aligned PVA/collagen composite nanofibrous electrospun scaffold," Nanomaterials, vol. 8, no. 2, 124 pages, 2018.

[23] Z. Chen, B. Wei, X. Mo, C. T. Lim, S. Ramakrishna, and F. Cui, "Mechanical properties of electrospun collagen-chitosan complex single fibers and membrane," Materials Science and Engineering: C, vol. 29, no. 8, pp. 2428-2435, 2009.

[24] Z. G. Chen, P. W. Wang, B. Wei, X. M. Mo, and F. Z. Cui, "Electrospun collagen-chitosan nanofiber: a biomimetic extracellular matrix for endothelial cell and smooth muscle cell," Acta Biomaterialia, vol. 6, no. 2, pp. 372-382, 2010.

[25] G. P. Huang, S. Shanmugasundaram, P. Masih et al., "An investigation of common crosslinking agents on the stability of electrospun collagen scaffolds," Journal of Biomedical Materials Research Part A, vol. 103, no. 2, pp. 762-771, 2015.

[26] C. Dhand, S. T. Ong, N. Dwivedi et al., "Bio-inspired in situ crosslinking and mineralization of electrospun collagen scaffolds for bone tissue engineering," Biomaterials, vol. 104, pp. 323-338, 2016.

[27] M. Jafari-Sabet, H. Nasiri, and R. Ataee, "The effect of crosslinking agents and collagen concentrations on properties of collagen scaffolds," Journal of Archives in Military Medicine, vol. 4, no. 4, 2016.

[28] A. B. Caruso and M. G. Dunn, "Changes in mechanical properties and cellularity during long-term culture of collagen fiber ACL reconstruction scaffolds," Journal of Biomedical Materials Research Part A, vol. 73, no. 4, pp. 388-397, 2005. 
[29] N. Rajan, J. Habermehl, M.-F. Cote, C. J. Doillon, and D. Mantovani, "Preparation of ready-to-use, storable and reconstituted type I collagen from rat tail tendon for tissue engineering applications," Nature Protocols, vol. 1, no. 6, p. $2753,2006$.

[30] Z. Movasaghi, S. Rehman, and I. U. Rehman, "Raman spectroscopy of biological tissues," Applied Spectroscopy Reviews, vol. 42, no. 5, pp. 493-541, 2007.

[31] L. S. Sefcik, R. A. Neal, S. N. Kaszuba et al., "Collagen nanofibres are a biomimetic substrate for the serum-free osteogenic differentiation of human adipose stem cells," Journal of Tissue Engineering and Regenerative Medicine, vol. 2, no. 4, pp. 210-220, 2008.

[32] J. Joshi, D. Brennan, V. Beachley, and C. R. Kothapalli, "Cardiomyogenic differentiation of human bone marrowderived mesenchymal stem cell spheroids within electrospun collagen nanofiber mats," Journal of Biomedical Materials Research Part A, vol. 106, no. 12, pp. 3303-3312, 2018.

[33] J. X. Law, L. L. Liau, A. Saim, Y. Yang, and R. Idrus, "Electrospun collagen nanofibers and their applications in skin tissue engineering," Tissue engineering and regenerative medicine, vol. 14, no. 6, pp. 699-718, 2017.

[34] C. Wang, J. Wang, L. Zeng et al., "Fabrication of electrospun polymer nanofibers with diverse morphologies," Molecules, vol. 24, no. 5, p. 834, 2019.

[35] M. Afshari, Electrospun Nanofibres, p. 648, Woodhead Publishing, Cambridge, UK, 2017.

[36] R. Kang, D. Q. Svend Le, H. Li et al., "Engineered three-dimensional nanofibrous multi-lamellar structure for annulus fibrosus repair," Journal of Materials Chemistry B, vol. 1, no. 40, pp. 5462-5468, 2013.

[37] T. Riaz, R. Zeeshan, F. Zarif et al., "FTIR analysis of natural and synthetic collagen," Applied Spectroscopy Reviews, vol. 53, no. 9, pp. 703-746, 2018.

[38] A. R. Costa-Pinto, A. M. Martins, M. J. Castelhano-Carlos et al., "In vitro degradation and in vivo biocompatibility of chitosan-poly (butylene succinate) fiber mesh scaffolds," Journal of Bioactive and Compatible Polymers, vol. 29, no. 2, pp. 137-151, 2014.

[39] J. Xiao, H. Duan, Z. Liu et al., "Construction of the recellularized corneal stroma using porous acellular corneal scaffold," Biomaterials, vol. 32, no. 29, pp. 6962-6971, 2011.

[40] M. Ghomi, Applications of Raman Spectroscopy to Biology: From Basic Studies to Disease Diagnosis, Vol. 5, IOS Press, Amsterdam, Netherland, 2012.

[41] E. Timchenko, P. Timchenko, L. Volova, S. Pershutkina, and P. Shalkovskaya, "Testing of Raman spectroscopy method for assessment of skin implants," Journal of Physics Conference Series (Online), vol. 769, 2016.

[42] R. Panneerselvam, N. Anandhan, K. P. Ganesan, T. Marimuthu, and I. J. Paneerdoss, "Effect of concentration on nano hydroxyapatite powder by wet chemical precipitation route," Asian Journal of Research in Chemistry, vol. 11, no. 3, pp. 545-550, 2018.

[43] S. Qiu, Y. Weng, Y. Li et al., "Raman profile alterations of irradiated human nasopharyngeal cancer cells detected with laser tweezer Raman spectroscopy," RSC Advances, vol. 10, no. 24, pp. 14368-14373, 2020.

[44] S. Farquharson, A. Gift, C. Shende et al., "Surface-enhanced Raman spectral measurements of 5 -fluorouracil in saliva," Molecules, vol. 13, no. 10, pp. 2608-2627, 2008.

[45] P. T. Freire, F. M. Barboza, J. A. Lima, F. E. Melo, and J. Mendes Filho, "Raman spectroscopy of amino acid crystals,"
Raman Spectroscopy and Applications, p. 201, IntechOpen, London, UK, 2017.

[46] S. H. Lee, S. Y. Park, and J. H. Choi, "Fiber formation and physical properties of chitosan fiber crosslinked by epichlorohydrin in a wet spinning system: the effect of the concentration of the crosslinking agent epichlorohydrin," Journal of Applied Polymer Science, vol. 92, no. 3, pp. 2054-2062, 2004.

[47] L. M. Hansen, D. J. Smith, D. H. Reneker, and W. Kataphinan, "Water absorption and mechanical properties of electrospun structured hydrogels," Journal of Applied Polymer Science, vol. 95, no. 2, pp. 427-434, 2005. 